\title{
Optimum Methods for Keeping the Abdomen Open
}

\author{
Mohammad A. Khasawneh ${ }^{1,2}$. Martin D. Zielinski ${ }^{1,2}$
}

Published online: 3 October 2016

(C) Springer International Publishing AG 2016

\begin{abstract}
Purpose of Review Damage control laparotomy, also known as an "open abdomen," is a life-saving maneuver frequently used to treat severely injured and emergency general surgery patients.

Recent Findings Several techniques exist to keep the abdomen open; temporary abdominal closure methods have evolved over time from inexpensive, simple techniques to more advanced methods utilizing commercially available products with improving results.

Summary In this review, we describe the techniques of open abdomen management along with their advantages and drawbacks as well as advanced management of patients with open abdomens.
\end{abstract}

Keywords Open abdomen - Temporary abdominal closure * Damage control laparotomy

\section{Introduction}

Damage control laparotomy (DCL), also known as "open abdomen, OA," refers to the surgical technique where the abdominal cavity is entered and left open deliberately at the

This article is part of the Topical Collection on Abdominal Compartment Syndrome in Trauma

Martin D. Zielinski

zielinski.martin@mayo.edu

1 Division of Trauma, Critical Care and General Surgery, St. Mary's Hospital, Mayo Clinic, Mary Brigh 2-810, 1216 Second Street SW, Rochester, MN 55902, USA

2 Department of Surgery, Mayo Clinic, Rochester, MN, USA completion of an abdominal exploration [1]. Most commonly described in trauma patients, DCL is a life-saving maneuver in which the surgeon accepts that portions of the procedure will not be completed [2]. This technique ensures hemorrhage and sepsis source control has been obtained to the best of the surgeon's ability. Once the abdominal domain has been maintained, albeit temporarily, the patient is rapidly transferred to the intensive care unit (ICU) for ongoing resuscitation [3, 4]. Re-exploration and definitive treatment of injuries are usually undertaken within 24-72 h of the index operation.

The use of packing to manage hepatic hemorrhage was originally described by Pringle and Halsted in their respective landmark papers in 1908 and 1913 [5, 6]. Their technique was widely adopted through World War II when primary repair reemerged as standard of care due to emerging improvements in surgical technique and resources [7]. The late 1970s and early 1980s saw resurgence in the use of DCL $[5,6]$. OA in the setting of emergency general surgery (EGS), specifically for acute suppurative peritonitis, was described by Steinberg in 1979 [8]. Following his publication, several reports described management of infected pancreatic necrosis with open abdomen management $[9,10]$.

Furthermore, in a prospective evaluation to treat liver injuries, Lucas and Ledgerwood reported acceptable outcomes for treating major hepatic injuries using similar techniques [11]. In the modern era, the concept of damage control resuscitation and utilization of open abdomen in trauma was popularized by Rotondo and Moore in the early 1990s [12, 13]. After dissemination of their source control methods coupled with early resuscitation in the ICU, DCL gained widespread acceptance. As a result of this popularity, multiple techniques to facilitate re-exploration have been developed. To this date, there is absence of Level I evidence data about optimal management of patients with open abdomen. This has led to multi-institutional and worldwide collaborations to help us better understand and 
improve care for this patient population [14]. It is the aim of this chapter to describe the techniques of open abdomen management along with their advantages and drawbacks.

\section{Risks Associated with the Open Abdomen}

When the decision is made to abbreviate the procedure and keep the abdomen open, the surgeon must start thinking about timing and method of achieving closure, as there are many risks associated with OA. Fluid loss from open abdomen is estimated to be $1 \mathrm{cc} / \mathrm{kg}$ per hour [15]. Each liter removed contains $2 \mathrm{~g}$ of protein, leading to a significant nutritional loss in the critically ill patient [16]. Hypothermia is another major complication which may aggravate acidosis and coagulopathy. Coverage of the viscera prevents heat loss due to evaporation and radiation, and is associated with improved outcomes $[17,18]$. Loss of domain, which can lead to failure of fascial closure and development of ventral hernia, is another major risk of OA. Failure of primary fascial closure can result in surgical site infection and enterocutaneous fistulae formation, leading to significant morbidity [19-21].

\section{Techniques}

Several techniques exist to keep the abdomen open. Ideally, these temporary abdominal closure (TAC) techniques should provide several features: (1) rapid access to the peritoneal cavity for re-exploration, (2) tension-free fascial closure to the prevent rise in intra-abdominal pressure, (3) facilitate fascial closure at the appropriate time, and (4) serve as a barrier to the external environment while safely covering the abdominal viscera and preventing fluid losses [22, 23]. TAC methods have evolved over time from inexpensive, simple techniques to more advanced methods utilizing commercially available products. While there is a lot of literature reported for types of TAC, there are relatively few studies which directly compare techniques. In fact, there are limited Level I recommendations in this field with only limited number of randomized trials

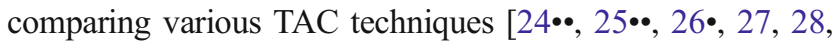
$29 \bullet \bullet, 30 \bullet$. In a multi-institutional, randomized trial, we evaluated the effect of chemically induced paralysis of the lateral abdominal wall on primary fascial closure rates. Patients were randomized to ultrasound-guided injections of their abdominal wall muscles with either Botox or placebo. Primary fascial closure rates were high in both groups: $96 \%$ for Botox and $93 \%$ for placebo $[31,32 \bullet \cdot]$.

\section{Skin Re-approximation}

Re-approximating the skin is the simplest, cheapest method of achieving TAC. While there are multiple methods to facilitate skin closure, the most common uses skin suturing with a running monofilament or perforating towel clamps placed along the length of the abdominal incision [33,34]. The clamp points are placed into the skin on both sides of the open incision and spaced 1 to $2 \mathrm{~cm}$ apart (Fig. 1). This method, although relatively straightforward to accomplish, has many disadvantages. Fixed approximation of the skin without the ability to drain excess abdominal fluid may result in increased in intra-abdominal pressure, especially during the resuscitation phase of damage control [35]. Additionally, injury to the skin edges can increase the risk of infection. Perhaps most importantly, the abdominal wall fascia is not re-approximated which can result in a loss of abdominal domain making the definitive closure more challenging [36]. Other disadvantages include extra nursing care if peritoneal fluid leaks between the skin edges. For these reasons, the authors do not recommend this technique unless no other option is available.

\section{The Silo Closure (aka "Bogota Bag”)}

The Bogota Bag technique, originally described by surgeons in Bogota, Columbia, is performed using a pre-sterilized, 3-1 plastic cystoscopy fluid irrigation bag. The bag is cut open, tailored to size, and sutured or stapled to the skin (Fig. 2) [38]. The technique was widely adopted in the past due to ease of application, broad availability, and low cost. Similarly to the skin re-approximation technique, Bogota Bag closure does not allow for the removal of excess peritoneal fluid thereby increasing the risk of intra-abdominal hypertension and abdominal compartment syndrome as well as increasing the challenges for nursing staff trying to keep the patient's abdominal skin dry. Again, loss of abdominal domain and skin trauma remain other potential complications. A modification has been made to this technique to overcome these issues. Rather than a single bag, two plastic IV bags, one placed between the viscera and abdominal wall, and one sutured to the skin, can be used. Trans-fascial sutures between the bags function as dynamic retention sutures to prevent abdominal domain loss

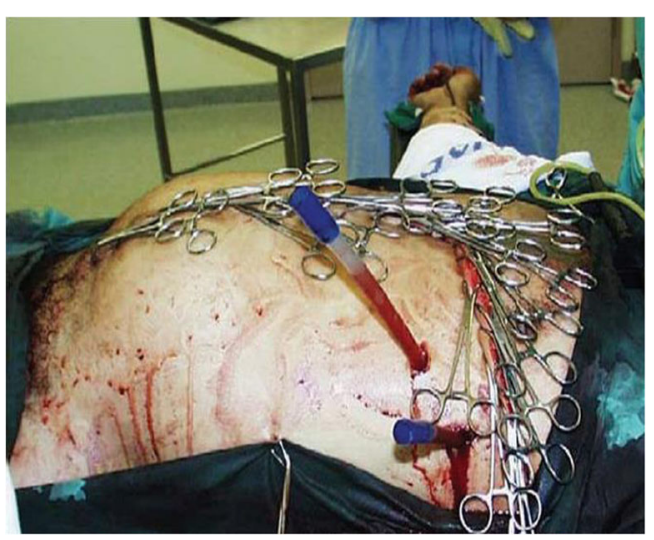

Fig. 1 Towel-clip closure. Reprinted from Qian Huang et al. [23], p. 15 


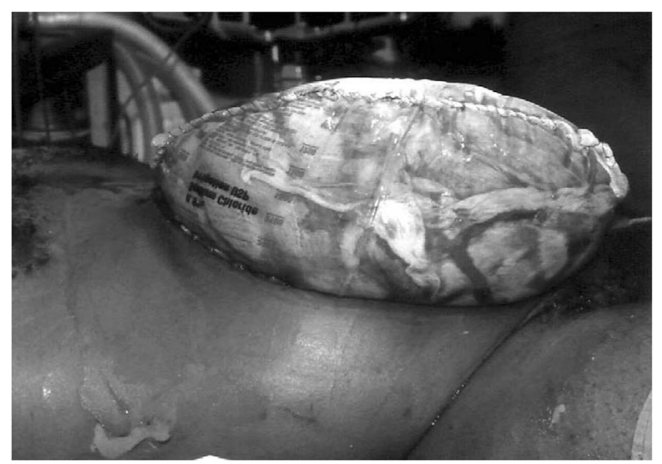

Fig. 2 Bogotá bag. Reprinted with permission from Rutherford et al. [37]

[39]. Reported primary fascial closure rate using this technique varies, but can be as high as $82 \%$ [36, 40, 41]. Moreover, long-term ventral hernia occurrence can be present in up to $60 \%$ of patients [42]. In a limited-resource environment where no other alternatives exist, the Bogota Bag TAC technique may be a viable option.

\section{Wittmann-Patch ${ }^{\circledR}$ (NovoMedicus, Germany)}

This technique achieves TAC by suturing two patches to each side of the fascia with a non-absorbable suture. The two sheets adhere to each other with a Velcro-like mechanism as one sheet consists of micro-mushrooms (i.e., hooks) and the second is made up of multiple slings which catch and hold the micro-mushrooms [43]. This provides easy access for re-exploration. A primary advantage of this technique is that it allows for serial re-approximation of the fascia by tightening the patch and cutting off the excess material. Eventually, the fascia will be mobilized sufficiently to the midline to allow for primary fascial closure. These serial tightening procedures can even be performed in the patient's bed in intensive care unit [44]. In a retrospective review, the technique was associated with an improved delayed primary fascial closure rate by $48 \%$ over other various TAC techniques (i.e., silo, vac-pack, absorbable mesh) $\left[45 \bullet^{\circ}\right.$. Primary fascial closure rate has even been reported to be as high as $94 \%$ [46]. One of the disadvantages of this method is tissue injury due to excessive tension on the fascial edges. As a result, fascial inflammation and necrosis may ensue, which may hinder the healing process, and increase rates of ventral herniae [24••, 46]. Long-term data on hernia rates after primary fascial closure using the Wittmann-Patch is lacking.

\section{Mesh Closure}

Permanent, biologic, and synthetic absorbable mesh prostheses can be used to achieve TAC. The method of closure is similar no matter the type of mesh utilized; the mesh is circumferentially sutured to the rectus abdominus fascial edges using running or interrupted sutures (Fig. 3) [48-50,

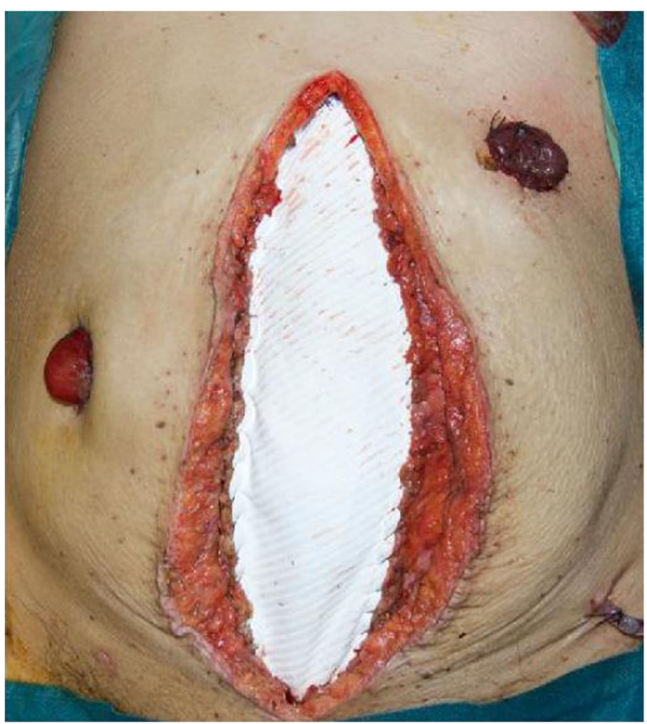

Fig. 3 Polytetrafluoroethylene (ePTFE) mesh used to cover abdominal contents. Reprinted with permission from Robin-Lersundi et. al. [47]

51•]. A negative pressure dressing is generally applied to provide extra tension and facilitate the removal of excessive peritoneal fluid. Mesh closure is relatively easy to perform, enables rapid access to the abdominal cavity, prevents retraction of the abdominal fascia, and improves primary fascial closure rates. Primary fascial closure rates have been reported to be up to $89 \%$ when using permanent mesh [50]. Permanent mesh, however, is not generally recommended to facilitate PFC as enterocutaneous fistula formation rate is high, up to $50 \%$ [48, 52]. Polytetrafluoroethylene (PTFE) may be an exception, however, as bowel and other intra-abdominal viscera do not tend to adhere and there appears to be a low risk of enterocutaneous fistula formation [53]. Polypropylene mesh may be more resistant to infection and allows for skin grafting, while PTFE mesh does not. GORE-TEX® DUALMESH ${ }^{\circledR}$ has also been used to manage the OA [54]. The mesh does not adhere to the underlying bowel, but is expensive, cannot be used in infected fields, and lacks porosities which do not allow for fluid removal. Biologic mesh has also been used. In a prospective case series of 10 patients with OA managed with Human Acellular Dermal Matrix (Alloderm ®, Lifecell), infection and enterocutaneous rates were low. However, all patients developed ventral hernia at 1 year follow-up [55]. Lastly, the only randomized controlled trial studying two different methods of TAC compared Polyglactin 910 (Vicryl ${ }^{\circledR}$ ) to negative pressure dressing. There were no differences between the two techniques in delayed primary fascial closure rates, negative pressure $(31 \%)$ and mesh $(26 \%)$. Although not statically significant, complication rate, specifically enterocutaneous fistula, was higher in patients treated with negative pressure dressing $(21 \%)$ compared to mesh $(5 \%)[30 \bullet]$. 


\section{Negative Pressure TAC}

Negative pressure therapy is done using a vacuum device. There are both commercial and non-commercial options created out of items commonly available in the operating room. First described by Barker and colleagues, the vacuum pack is constructed in layers: a porous $10103 \mathrm{M}^{\mathrm{TM}}$ Steri-Drape ${ }^{\mathrm{TM}}$ sheet is placed underneath the peritoneum to cover the viscera, a surgical towel or KERLIX ${ }^{\mathrm{TM}}$ gauze over the sheet, JacksonPratt (JP) drains, an adhesive drape $3 \mathrm{M}^{\mathrm{TM}}$ Ioban $^{\mathrm{TM}}$ to cover the entire wound [56]. The JP drains are connected to a wall suction outlet which provided continuous negative pressure. This method is relatively cheap, easily applied, and easy to make if commercial devices are not readily available. The main drawback of this technique is decreased primary fascial closure rates and unequal distribution of suction throughout the abdominal cavity, leading to intra-abdominal fluid accumulation. In a single-institution retrospective review, the primary fascial closure rate using this method was $52 \%$ [56].

In 2001, Garner and colleagues reported use of the KCI Vacuum-Assisted Closure System for TAC, a polyurethane foam sponge was utilized as a substitute to surgical towel over the Steri-Drape ${ }^{\mathrm{TM}}$ barrier into which suction tubing was connected [57]. The authors reported a primary fascial closure rate of $92 \%$, but this experience was limited by small patient population. Miller and colleagues were able to show similar outcomes [58]. Caution must be taken to avoid direct contact between sponge and bowel, as this may result in erosion of the bowel wall and fistula formation. Newer generation of vacuum-assisted closure system consists of a non-adherent fenestrated polyurethane drape for protection of viscera (Fig. 4). Prospective evaluation has revealed rates of primary fascial closure ranging from 69 to $82 \%$ [59]. In vitro study evaluating pressure distribution between three negative pressure TAC techniques revealed that approaches to negative pressure therapy for open abdomen treatment are not equal. The study suggests that newer commercially available devices have better pressure distribution, the clinical implications of this finding is yet to be determined [60].

\section{Dynamic Retention Sutures}

Several methods of retention sutures have been described, often used in conjunction with negative pressure TAC. Trans-fascial sutures are placed to provide continuous medial tension on the abdominal wall, thus preventing lateral retraction. This can be achieved using vessel loops or heavy nonabsorbable suture material. Studies have shown an increased rate of fascial closure. In a report of 100 consecutive patients treated with vacuum-assisted closure and no. 1polydioxanone (PDS) sutures, primary fascial closure was achieved in all patients [61••]. In another retrospective review, delayed primary fascial closure rate was $87 \%$ with low

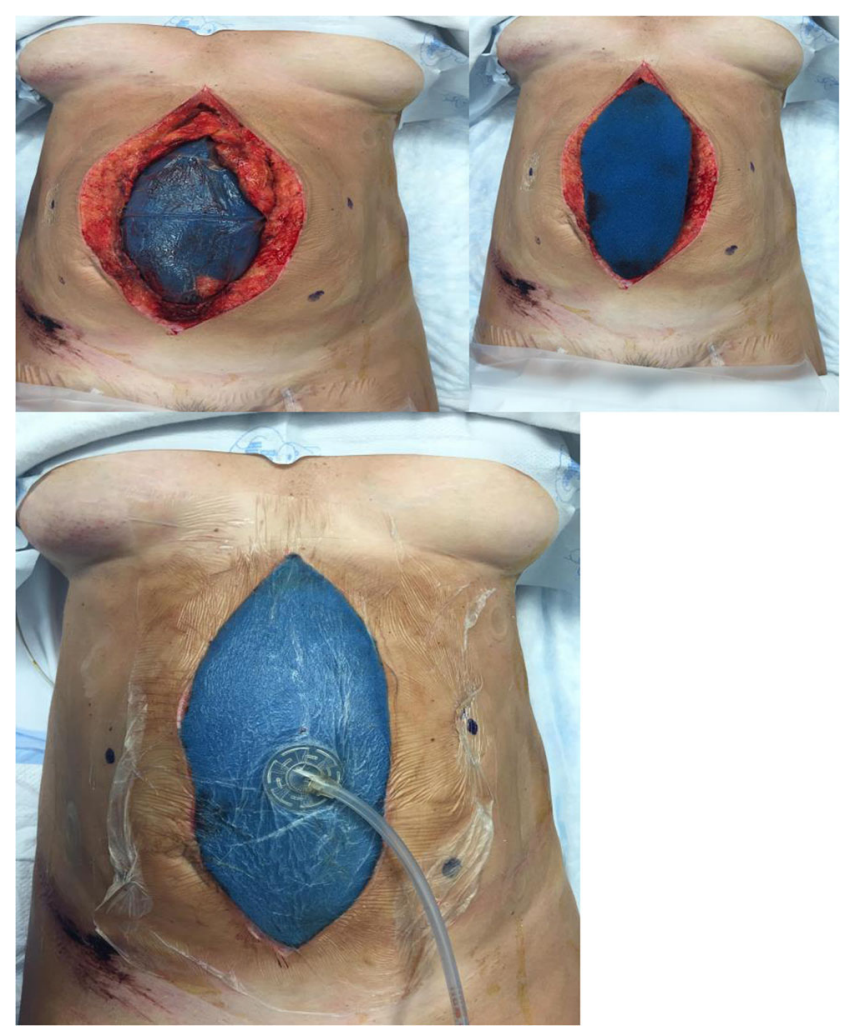

Fig. 4 ABThera ${ }^{\mathrm{TM}}$ open abdomen negative pressure therapy

infection (4\%) and enterocutaneous rates (3\%) [62]. Additionally, a retrospective study of 16 OA patients treated with continuous retention sutures showed complete fascial closure in $82 \%$ of patients [63]. Given these encouraging results and low complication rates, retention sutures are routinely placed in our practice.

\section{Clinical Management of Patients with Open Abdomen}

Intra-abdominal hypertension and acute abdominal compartment syndrome are very common in trauma and critically ill patients. If left untreated, mortality from this condition is high $[64,65]$. In a prospective study, 33 patients with abdominal compartment syndrome were treated with decompressive laparotomy. Having the abdomen open resulted in immediate reduction in intra-abdominal pressure and significant improvement in end organ perfusion and function [66]. When acute compartment syndrome is suspected, the diagnosis can be confirmed with measurement of bladder pressure [67].

The ultimate goal of TAC is to improve the odds of mortality for emergency surgical and trauma patients by abbreviated laparotomy and rapid reversal of acidosis, hypothermia, and coagulopathy using damage control resuscitation. A major secondary goal of this process, however, is to ensure delayed primary fascial closure. The techniques outlined above 
all will facilitate these goals to varying degrees. While these techniques are necessary, they are not sufficient. There are adjuncts to these techniques which may increase the rates of primary fascial closure to the greatest rate possible.

All institutions which have the possibility of performing damage control surgery must have a protocol in place outlining the steps needed to facilitate the original TAC. This protocol must extend into the immediate post-operative period by outlining the timing and technique of abdominal reexploration. With this type of an approach, rates nearing $100 \%$ primary fascial closure are possible when the protocol is adhered to $[61 \bullet \bullet]$. A large portion of this success may be attributable to planned serial re-exploration at every $48 \mathrm{~h}$. When this was not done, rates of primary fascial closure plummeted to $55 \%$. In the largest prospective, multiinstitutional trial to date of trauma patients undergoing TAC, every hour delay in re-exploration decreased the risk of primary fascial closure by $1.1 \%$ [68••]. Moreover, leaving the abdomen open for a longer period increases the risk of microbial colonization of the wound. But this has not been shown to increase wound complications or enterocutaneous fistula formation [69].

Excessive fluid administration can lessen rates of primary fascial closure. Out of 181 non-trauma patients undergoing TAC management, patients who did not achieve primary fascial closure had a greater cumulative fluid balance through post-operative day 10 [70]. This excessive rate of fluid administration was linked temporally to the development of sepsis and other infectious complications including intra-abdominal abscess and enterocutaneous fistula formation. Avoiding these complications may lower fluid requirements thereby increasing primary fascial closure rates. Previously thought of an anathema enteral feeding in the setting of TAC has been shown to be safe and associated with lower rates of infectious complications including pneumonia [71•]. While the mechanism for this benefit of feeding remains unknown, it is theorized that enteral feeding provides trophic factors critical in maintaining tight junctions of the gastrointestinal mucosa [72].

\section{Conclusion}

There are many methods surgeons can use to keep the abdomen open. While the primary goal of these TAC techniques is to improve mortality for critically ill surgical patients by facilitating damage control resuscitation, obtaining primary fascial closure once the critical illness has been successfully treated remains paramount. Not only is the correct utilization of TAC techniques necessary to ensure the highest rates of primary fascial closure, but also the continued involvement of the surgeon via protocols and avoidance of complications is critical.

\section{Compliance with Ethical Standards}

Conflict of Interest Drs. Khasawneh and Zielinski declare no conflicts of interest relevant to this manuscript.

Human and Animal Rights and Informed Consent This article does not contain any studies with human or animal subjects performed by any of the authors.

\section{References}

Papers of particular interest, published recently, have been highlighted as:

- Of importance

•. Of major importance

1. Leppaniemi AK. Laparostomy: why and when? Crit Care. 2010;14: 216.

2. Waibel BH, Rotondo MF. Damage control in trauma and abdominal sepsis. Crit Care Med. 2010;38:S421-30.

3. Dellinger RP, Carlet JM, Masur H, et al. Surviving sepsis campaign guidelines for management of severe sepsis and septic shock. Crit Care Med. 2004;32:858-73.

4. Cotton BA, Reddy N, Hatch QM, et al. Damage control resuscitation is associated with a reduction in resuscitation volumes and improvement in survival in 390 damage control laparotomy patients. Ann Surg. 2011;254:598-605.

5. Pringle JH. V. Notes on the arrest of hepatic hemorrhage due to trauma. Ann Surg. 1908;48:541-9.

6. Halsted SW. Ligature and suture material: the employment of fine silk in preference to catgut and the advantages of transfixing tissues and vessels in controlling hemorrhage-also an account of the introduction of gloves, gutta-percha tissue and silver foil. JAMA 1913; 60:1119-1126.

7. Carmona RH, Peck DZ, Lim Jr RC. The role of packing and planned reoperation in severe hepatic trauma. J Trauma. 1984;24: 779-84.

8. Steinberg D. On leaving the peritoneal cavity open in acute generalized suppurative peritonitis. Am J Surg. 1979;137:216-20.

9. Pemberton JH, Nagorney DM, Becker JM, Ilstrup D, Dozois RR, Remine WH. Controlled open lesser sac drainage for pancreatic abscess. Ann Surg. 1986;203:600-4.

10. Bradley 3rd EL. Management of infected pancreatic necrosis by open drainage. Ann Surg. 1987;206:542-50.

11. Lucas CE, Ledgerwood AM. Prospective evaluation of hemostatic techniques for liver injuries. J Trauma. 1976;16:442-51.

12. Rotondo MF, Schwab CW, McGonigal MD, et al. 'Damage control': an approach for improved survival in exsanguinating penetrating abdominal injury. J Trauma. 1993;35:375-82. discussion 82-3.

13. Moore EE, Burch JM, Franciose RJ, Offner PJ, Biffl WL. Staged physiologic restoration and damage control surgery. World J Surg. 1998;22:1184-90. discussion 90-1.

14. Coccolini F, Catena F, Montori G, et al. IROA: the International Register of Open Abdomen: an international effort to better understand the open abdomen: call for participants. World J Emerg Surg. 2015;10:37. 
15. Lamke LO, Nilsson GE, Reithner HL. Water loss by evaporation from the abdominal cavity during surgery. Acta Chir Scand. 1977;143:279-84.

16. Cheatham ML, Safcsak K, Brzezinski SJ, Lube MW. Nitrogen balance, protein loss, and the open abdomen. Crit Care Med. 2007;35: 127-31.

17. Asensio JA, Petrone P, Roldan G, Kuncir E, Ramicone E, Chan L. Has evolution in awareness of guidelines for institution of damage control improved outcome in the management of the posttraumatic open abdomen? Arch Surg. 2004;139:209-14. discussion 15.

18. Dutton WD, Diaz Jr JJ, Miller RS. Critical care issues in managing complex open abdominal wound. J Intensive Care Med. 2012;27: $161-71$.

19. Johnson JW, Gracias VH, Schwab CW, et al. Evolution in damage control for exsanguinating penetrating abdominal injury. J Trauma. 2001;51:261-9. discussion 9-71.

20. Miller RS, Morris Jr JA, Diaz Jr JJ, Herring MB, May AK. Complications after 344 damage-control open celiotomies. J Trauma. 2005;59:1365-71. discussion 71-4.

21. Teixeira PGR, Salim A, Inaba K, et al. A prospective look at the current state of open abdomens. Am Surg. 2008;74:891-7.

22. Coccolini F, Biffl W, Catena F, et al. The open abdomen, indications, management and definitive closure. World J Emerg Surg. 2015;10:32.

23. Huang Q, Li J, Lau WY. Techniques for abdominal wall closure after damage control laparotomy: from temporary abdominal closure to early/delayed fascial closure - a review. Gastroenterol Res Pract. 2016;2016:2073260.

24.• Diaz JJ, Jr., Cullinane DC, Dutton WD, et al. The management of the open abdomen in trauma and emergency general surgery: part 1damage control. J Trauma 2010;68:1425-38. This is a review article that included prospective and retrospective studies about managing patients with an open abdomen. The authors concluded that every institution should have a protocol to manage patients with an open abdomen.

25.• Henteleff HJ, Parry NG, Burlew CC. What is the comparative efficacy of negative-pressure wound therapy vs alternate temporary abdominal closure techniques in open abdominal wounds? J Am Coll Surg. 2014;218:1251-3. Review article that included 2 randomized controlled trials (RCT) and 9 cohort studies. Negative pressure closure device was compared to other methods of temporary abdominal closure. The authors concluded that negative pressure closure devices are associated with better outcomes, mainly in primary fascial closure rates.

26. Pliakos I, Papavramidis TS, Mihalopoulos N, et al. Vacuumassisted closure in severe abdominal sepsis with or without retention sutured sequential fascial closure: a clinical trial. Surgery 2010;148:947-53. Randomized controlled trial that compared vacuum-assisted closure (VAC) technique to VAC with retention sutures. Patients who had retention sutures in addition to VAC closure had better outcomes; greater primary fascial closure rates, and shorter hospital stay.

27. Long KL, Hamilton DA, Davenport DL, Bernard AC, Kearney PA, Chang PK. A prospective, controlled evaluation of the abdominal reapproximation anchor abdominal wall closure system in combination with VAC therapy compared with VAC alone in the management of an open abdomen. Am Surg. 2014;80:567-71.

28. Robledo FA, Luque-de-Leon E, Suarez R, et al. Open versus closed management of the abdomen in the surgical treatment of severe secondary peritonitis: a randomized clinical trial. Surg Infect. 2007;8:63-72.

29.• Kirkpatrick AW, Roberts DJ, Faris PD, et al. Active negative pressure peritoneal therapy after abbreviated laparotomy: the intraperitoneal vacuum randomized controlled trial. Ann Surg. 2015;262: 38-46. A single-center randomized controlled trial that included 54 patients treated with either ABThera or Baker's vacuum pack. The primary endpoint was the difference in the plasma concentration of inflammatory markers after temporary abdominal closure application. A survival difference was detected between patients randomized to the ABThera versus Barker's vacuum pack. However, that did not seem to be mediated by an improvement in peritoneal fluid drainage, fascial closure rates, or markers of systemic inflammation.

30. Bee TK, Croce MA, Magnotti LJ, et al. Temporary abdominal closure techniques: a prospective randomized trial comparing polyglactin 910 mesh and vacuum-assisted closure. J Trauma. 2008;65:337-42; discussion 42-4. A prospective randomized trial that included 51 patients. Patients were randomized to either vacuum-assisted closure or polyglactin mesh closure after damage control laparotomy. There were no differences between delayed primary fascial closure rates in both groups.

31. Zendejas B, Khasawneh MA, Srvantstyan B, Jenkins DH, Schiller HJ, Zielinski MD. Outcomes of chemical component paralysis using botulinum toxin for incisional hernia repairs. World J Surg. 2013;37:2830-7.

32.• Zielinski MD, Kuntz M, Zhang X, et al. Botulinum toxin A-induced paralysis of the lateral abdominal wall after damage-control laparotomy: a multi-institutional, prospective, randomized, placebocontrolled pilot study. J Trauma Acute Care Surg. 2016;80:23742. A multi-institutional, prospective, randomized, placebocontrolled pilot study. The study included 46 patients that were randomized to either to receive ultrasound-guided injections of their external oblique, internal oblique, and transversus abdominus muscles with either Botox $(150 \mathrm{~mL}, 2 \mathrm{U} / \mathrm{mL})$ or placebo $(150-\mathrm{mL} 0.9 \% \mathrm{NaCl})$. The use of Botox after open abdomen was safe but did not seem to affect primary fascial closure, hospital length of stay, or pain modulation.

33. Feliciano DV, Burch JM. Towel clips, silos and heroic forms of wound closure. Advances in Trauma and Critical Care. St Louis: Mosby-YearBook; 1991;6:235-50.

34. Smith PC, Tweddell JS, Bessey PQ. Alternative approaches to abdominal wound closure in severely injured patients with massive visceral edema. J Trauma. 1992;32:16-20.

35. Campbell A, Chang M, Fabian T, et al. Management of the open abdomen: from initial operation to definitive closure. Am Surg. 2009;75:S1-22.

36. Tremblay LN, Feliciano DV, Schmidt J, et al. Skin only or silo closure in the critically ill patient with an open abdomen. Am J Surg. 2001;182:670-5.

37. Rutherford EJ et al. Management of the patient with an open abdomen: techniques in temporary and definitive closure. Curr Probl Surg. 2004;41(10):825.

38. Fernandez L, Norwood S, Roettger R, Wilkins 3rd HE. Temporary intravenous bag silo closure in severe abdominal trauma. J Trauma. 1996;40:258-60.

39. Joglar F, Agosto E, Marrero D, Canario QM, Rodriguez P. Dynamic retention suture closure: modified Bogota bag approach. J Surg Res. 2010;162:274-8.

40. Kirshtein B, Roy-Shapira A, Lantsberg L, Mizrahi S. Use of the "Bogota bag" for temporary abdominal closure in patients with secondary peritonitis. Am Surg. 2007;73:249-52.

41. Batacchi S, Matano S, Nella A, et al. Vacuum-assisted closure device enhances recovery of critically ill patients following emergency surgical procedures. Crit Care. 2009;13:R194.

42. Manterola C, Moraga J, Urrutia S. Contained laparostomy with a Bogota bag. Results of case series. Cir Esp. 2011;89:379-85.

43. Wittmann DH, Aprahamian C, Bergstein JM, et al. A burr-like device to facilitate temporary abdominal closure in planned multiple laparotomies. Eur J Surg. 1993;159:75-9.

44. Tieu BH, Cho SD, Luem N, Riha G, Mayberry J, Schreiber MA. The use of the Wittmann Patch facilitates a high rate of fascial closure in severely injured trauma patients and critically ill emergency surgery patients. J Trauma. 2008;65:865-70. 
45.• Weinberg JA, George RL, Griffin RL, et al. Closing the open abdomen: improved success with Wittmann Patch staged abdominal closure. J Trauma. 2008;65:345-8. A retrospective cohort study that compared outcomes of patients treated with Wittmann Patch closure. The authors concluded that Wittmann Patch contributed to an increased incidence of delayed fascial closure. Patch closure didn't affect complication rates.

46. Aprahamian C, Wittmann DH, Bergstein JM, Quebbeman EJ. Temporary abdominal closure (TAC) for planned relaparotomy (etappenlavage) in trauma. J Trauma. 1990;30:719-23.

47. Robin-Lersundi A et al. Temporary abdominal closure with polytetrafluoroethylene prosthetic mesh in critically ill nontrauma patients. Hernia. 2015;19(2):329-37.

48. Fansler RF, Taheri P, Cullinane C, Sabates B, Flint LM. Polypropylene mesh closure of the complicated abdominal wound. Am J Surg. 1995;170:15-8.

49. Nagy KK, Fildes JJ, Mahr C, et al. Experience with three prosthetic materials in temporary abdominal wall closure. Am Surg. 1996;62: 331-5.

50. Ciresi DL, Cali RF, Senagore AJ. Abdominal closure using nonabsorbable mesh after massive resuscitation prevents abdominal compartment syndrome and gastrointestinal fistula. Am Surg. 1999;65: 720-4. discussion 4-5.

51. Sutton PA, Evans JP, Uzair S, Varghese JV. The use of Gore Bio-A in the management of the open abdomen. BMJ Case Rep. 2013;2013. Article reporting the use of Gore Bio-A mesh in the setting of hollow viscus perforation and intra-abdominal contamination. The authors reported that use of Gore Bio-A is a safe, feasible and cost effective alternative to traditional biologics for the closure of an open abdomen.

52. Greene MA, Mullins RJ, Malangoni MA, Feliciano PD, Richardson JD, Polk Jr HC. Laparotomy wound closure with absorbable polyglycolic acid mesh. Surg Gynecol Obstet. 1993;176:213-8.

53. Cheatham ML, Safcsak K, Llerena LE, Morrow Jr CE, Block EF. Long-term physical, mental, and functional consequences of abdominal decompression. J Trauma. 2004;56:237-41. discussion $41-2$.

54. Vertrees A, Greer L, Pickett C, et al. Modern management of complex open abdominal wounds of war: a 5-year experience. J Am Coll Surg. 2008;207:801-9.

55. de Moya MA, Dunham M, Inaba K, et al. Long-term outcome of acellular dermal matrix when used for large traumatic open abdomen. J Trauma. 2008;65:349-53.

56. Barker DE, Kaufman HJ, Smith LA, Ciraulo DL, Richart CL, Burns RP. Vacuum pack technique of temporary abdominal closure: a 7-year experience with 112 patients. J Trauma. 2000;48:201-6. discussion 6-7.

57. Garner GB, Ware DN, Cocanour CS, et al. Vacuum-assisted wound closure provides early fascial reapproximation in trauma patients with open abdomens. Am J Surg. 2001;182:630-8.

58. Miller PR, Thompson JT, Faler BJ, Meredith JW, Chang MC. Late fascial closure in lieu of ventral hernia: the next step in open abdomen management. J Trauma. 2002;53:843-9.

59. Cheatham ML, Demetriades D, Fabian TC, et al. Prospective study examining clinical outcomes associated with a negative pressure wound therapy system and Barker's vacuum packing technique. World J Surg. 2013;37:2018-30.

60. Delgado A, Sammons A. In vitro pressure manifolding distribution evaluation of ABThera ${ }^{\mathrm{TM}}$ Active Abdominal Therapy System,
V.A.C. ${ }^{\circledR}$ Abdominal Dressing System, and Barker's vacuum packing technique conducted under dynamic conditions. SAGE Open Med. 2016;4:2050312115624988.

61.• Burlew CC, Moore EE, Biffl WL, Bensard DD, Johnson JL, Barnett CC. One hundred percent fascial approximation can be achieved in the postinjury open abdomen with a sequential closure protocol. J Trauma Acute Care Surg. 2012;72:235-41. Retrospective review of 100 consecutive patients treated with sequential closure technique. In this technique, temporary abdominal closure is achieved by placing negative pressure device in addition to placing retention sutures. The authors reported $100 \%$ fascial closure rates. This approach reduced morbidity of the open abdomen.

62. Kafka-Ritsch R, Zitt M, Schorn N, et al. Open abdomen treatment with dynamic sutures and topical negative pressure resulting in a high primary fascia closure rate. World J Surg. 2012;36:1765-71.

63. Gaddnas F, Saarnio J, Ala-Kokko T, Laurila J, Koivukangas V. Continuous retention suture for the management of open abdomen: a high rate of delayed fascial closure. Scand J Surg SJS Off Organ FinnSurg Soc Scand Surg Soc. 2007;96:301-7.

64. Hecker A, Hecker B, Hecker M, Riedel JG, Weigand MA, Padberg W. Acute abdominal compartment syndrome: current diagnostic and therapeutic options. Langenbeck's Arch Surg. 2016;401:1524.

65. Kuteesa J, Kituuka O, Namuguzi D, et al. Intra-abdominal hypertension; prevalence, incidence and outcomes in a low resource setting; a prospective observational study. World J Emerg Surg. 2015;10:57.

66. De Waele JJ, Kimball E, Malbrain M, et al. Decompressive laparotomy for abdominal compartment syndrome. Br J Surg. 2016.

67. Tiwari AR, Pandya JS. Study of the occurrence of intra-abdominal hypertension and abdominal compartment syndrome in patients of blunt abdominal trauma and its correlation with the clinical outcome in the above patients. World J Emerg Surg. 2016;11:9.

68.• Pommerening MJ, DuBose JJ, Zielinski MD, et al. Time to first take-back operation predicts successful primary fascial closure in patients undergoing damage control laparotomy. Surgery 2014;156: 431-8. Multicenter prospective study that included 499 patients who underwent damage control laparotomy. Primary closure rates were $65.5 \%$. Delays in returning to the operating room after damage control laparotomy was associated with reduction in primary fascial closure rate.

69. Rasilainen SK, Juhani MP, Kalevi LA. Microbial colonization of open abdomen in critically ill surgical patients. World J Emerg Surg. 2015;10:25.

70. Goussous N, Kim BD, Jenkins DH, Zielinski MD. Factors affecting primary fascial closure of the open abdomen in the nontrauma patient. Surgery. 2012;152:777-83. discussion 83-4.

71. Dissanaike S, Pham T, Shalhub S, et al. Effect of immediate enteral feeding on trauma patients with an open abdomen: protection from nosocomial infections. J Am Coll Surg. 2008;207:690-7. Multicenter prospective cohort study that aimed to determine the safety and effect of immediate enteral nutrition in patients with open abdomen. Immediate enteral nutrition after damage control was safe. There was a reduction in pneumonia rates in patients who had immediate enteral nutrition.

72. Tan SJ, Yu C, Yu Z, et al. High-fat enteral nutrition reduces intestinal mucosal barrier damage after peritoneal air exposure. J Surg Res. 2016;202:77-86. 